Review Article

\title{
A Review on Fault Mechanism and Diagnosis Approach for Li-Ion Batteries
}

\author{
Chao Wu, ${ }^{1,2}$ Chunbo Zhu, ${ }^{1}$ Yunwang Ge, ${ }^{2}$ and Yongping Zhao ${ }^{1}$ \\ ${ }^{1}$ School of Electrical Engineering and Automation, Harbin Institute of Technology, Harbin 150001, China \\ ${ }^{2}$ Department of Electrical Engineering, Luoyang Institute of Science and Technology, Luoyang 471023, China
}

Correspondence should be addressed to Chao Wu; shiningi@163.com

Received 8 January 2015; Accepted 4 March 2015

Academic Editor: Jiayu Wan

Copyright (C) 2015 Chao Wu et al. This is an open access article distributed under the Creative Commons Attribution License, which permits unrestricted use, distribution, and reproduction in any medium, provided the original work is properly cited.

Li-ion battery has attracted more and more attention as it is a promising storage device which has long service life, higher energy, and power density. However, battery ageing always occurs during operation and leads to performance degradation and system fault which not only causes inconvenience, but also risks serious consequences such as thermal runaway or even explosion. This paper reviews recent research and development of ageing mechanisms of Li-ion batteries to understand the origins and symptoms of Li-ion battery faults. Common ageing factors are covered with their effects and consequences. Through ageing tests, relationship between performance and ageing factors, as well as cross-dependence among factors can be quantified. Summary of recent research about fault diagnosis technology for Li-ion batteries is concluded with their cons and pros. The suggestions on novel fault diagnosis approach and remaining challenges are provided at the end of this paper.

\section{Introduction}

These years, Li-ion battery has been commercialized widely for the advantages such as long service life, high energy density, and environmental protection. It is considered as the most promising energy storage device in EV (electrical vehicle) field, which has gradually taken increasing rate in all vehicles sold. Along with the development of EV and Li-ion battery industry, BMS (battery management system) technology made rapid progress [1]. Basic BMS should provide the following functions [2]: (1) data acquisition, (2) SOC (state of charge), SOH (state of health) and SOF (state of health) estimation, (3) charge control, (4) equalization, and (5) thermal management. All these techniques were reported and reviewed frequently during the last twenty years $[3,4]$. However little attention has been paid to fault diagnosis technology for Li-ion batteries until several issues and accidents related to batteries occurred during recent years: batteries of laptops from Panasonic, Dell, and Sony were successively recalled for fire hazards; Tesla Model S EV had 5 fire accidents in last 6 months totally related to batteries; BYD electrical taxi caught a fire during charging process. All these events brought the safety issue of Li-ion batteries to public concern.
Although Li-ion batteries are known as long-service devices, their lives depend greatly on environmental condition and operation mode. Conditions such as elevated temperature and overcharging/overdischarging will shorten service life, so it is necessary for users to understand the ageing mechanism and detect faults before terrible accidents occur.

Faults of Li-ion batteries usually come from ageing process or abuse operation. Usually, the concept $\mathrm{SOH}$ is used for description of current status of health or remaining life [5]. However, it is not sufficient to describe one cell with only one variable, especially for diagnosis system. More information should be provided such as operation history and real-time variation to foresee further performance, and this is important for echelon use of Li-ion batteries $[6,7]$.

Fault diagnosis technology has been developed and applied in industrial applications in recent years with advanced models, algorithms and ideas. However, different from mechanical or pure electrical system, Li-ion battery is much more complex due to its electrochemical property. Hysteresis and inconsistency among cells make it even harder to directly extract the fault symptoms. Therefore fault diagnosis for Li-ion batteries requires completely understanding 


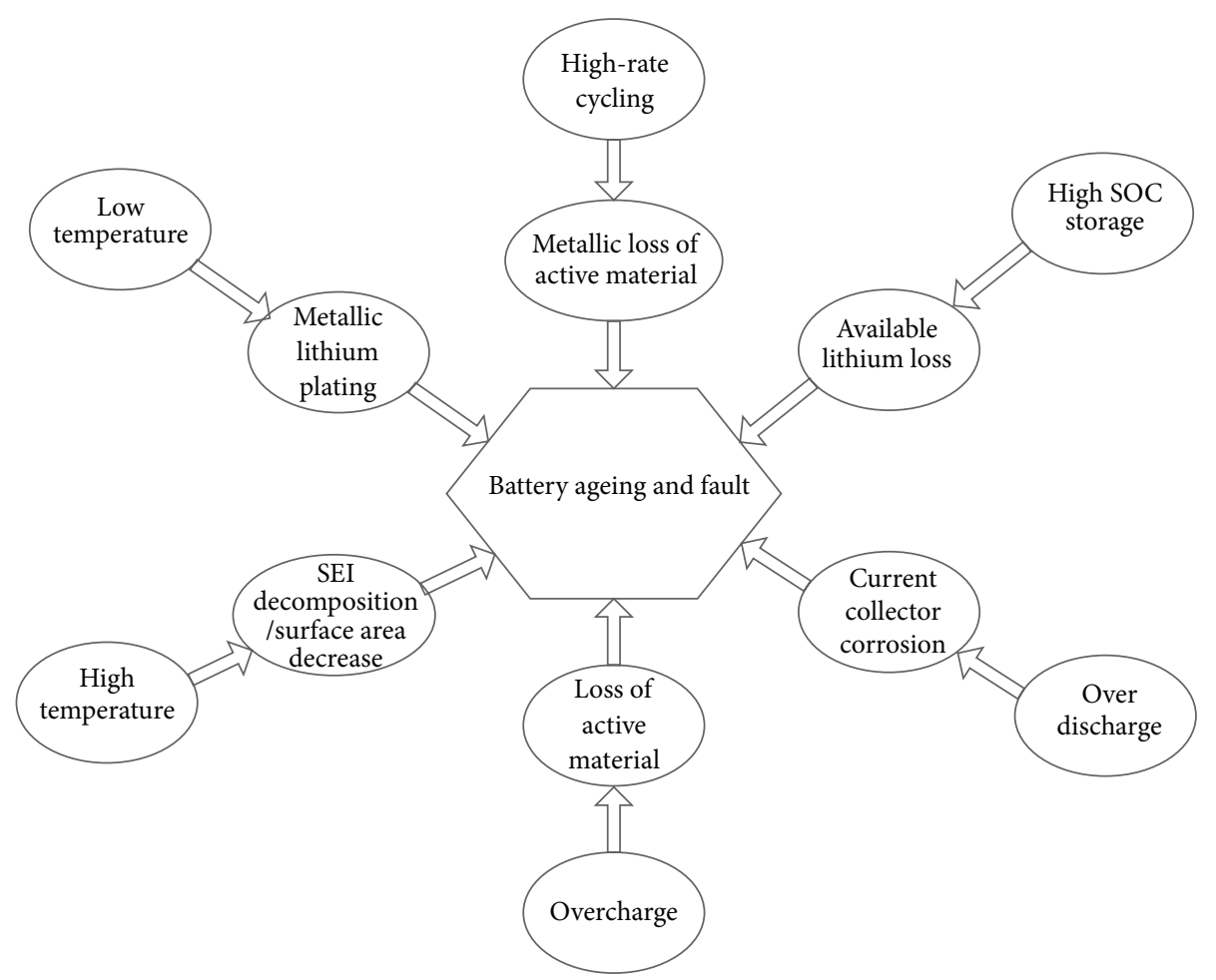

FIgURE 1: Causes for battery ageing at anode and their effects.

their ageing mechanism and certain advanced diagnosis technology.

This review intends to summarize recent achievements in fault diagnosis for Li-ion batteries, including the ageing mechanism, tests, and diagnosis methods. Subsequent sections of this paper are arranged as follows. Section 2 introduces the basic ageing mechanism of Li-ion batteries in electrochemical point of view. With the mechanism, accelerated tests are represented, trying to quantify performance degradation with one or more ageing factors. This content will be arranged in Section 3. After that, recent researches on fault diagnosis for Li-ion batteries are reviewed and compared in Section 4. Finally conclusion is drawn and we suggest a novel diagnosis method for batteries with reference of this review.

\section{Ageing Mechanism}

Battery ageing, usually in form of capacity fade and resistance growth, perhaps as well as available power fade, is one of the most challenging issues for system safety. Life predication and fault diagnosis technologies require a good understanding of this process [8-10]. The main ageing causes for Li-ion batteries are decomposition of SEI (Solid Electrolyte Interphase), deposition at anode $[11,12]$, metal dissolution from anode [13, 14], loss of active material [15] and lithium plating [16]. Since the degradation mechanisms from the positive and negative electrodes may be different, we will discuss the mechanism in view of electrode degradation.

2.1. Ageing at Anode. In this paper, only the most popular anode material graphite is discussed. Many researchers regarded the electrochemical changes at the electrode/electrolyte as the main cause for anode ageing [17, 18]. Decomposition products, which are caused by reductive electrolyte decomposition at the electrode/electrolyte interface, build up the so called "SEI" that covers the electrode's surface during the first few cycles. SEI is stable and has a rather slowly ageing process unless the battery operates at improper conditions such as elevated temperature or heavy cycles. High temperature accelerates SEI breakdown or dissolution and results in an increased degradation rate [19]. In case of overcharge or high SOC storage, gas from graphite exfoliation induces crack of SEI and loss of active area [20], while low temperature may lower lithium ion diffusion. In this case, SEI is covered by lithium plating and safety issue may occur due to metallic lithium plating and lithium dendrite growth. Other origins of anode ageing such as changes of active material, changes of composite electrode, and contact loss [21] will not be discussed in detail here. The factors of battery ageing occurring at anode and their main effects are summarized in Figure 1. Notice that these factors are not isolated and the relationships cannot be discussed separately. For example, both high-rate discharge and low temperature may limit ion diffusion while both high temperature and overcharge perform an additive energy directly into batteries. This content will be discussed in Section 3 with corresponding test procedure and quantitative research.

2.2. Ageing at Cathode. Bourlot et al. reported that there was no evident change of the cathode morphology, for all levels of battery utilization. The author quantified the ratio of active $\mathrm{Li} /$ metal at anode and active lithium in 
wt $\%$ at cathode. For aged batteries, more active lithium at cathode was observed with low-rate discharge to $0.5 \mathrm{~V}$ compared with fresh batteries. The author attributed this to limitation of anode, which was the main effect of ageing mechanism [22]. Although the changes at cathode seem to have less influences on battery ageing than those at anode [23], the influence indeed exists. SEI also forms at the interface [24], and it experiences the same process of growing, ageing, and decomposition. The ageing originates from SEI decomposition, changes of composite electrode and chemical decomposition, and dissolution reaction and differs according to the composition of cathode as well. The most popular chemistries in current production are $\mathrm{LiCoO}_{2}$, $\mathrm{LiMn}_{2} \mathrm{O}_{4}$, and $\mathrm{LiFePO}_{4}$. These cathode materials have their advantages and disadvantages. For example, $\mathrm{LiFePO}_{4}$ is attractive because of its high stability, low cost, and high compatibility with environment. Major disadvantages lie on its low electrical conductivities and slow diffusion rates of $\mathrm{Li}$ ions. Conductive additives may be an available approache to overcome their own drawbacks. Carbon nanotube has been proven to be the most effective one in improving the electrochemical performance and guaranteeing the safety of the composite cathode.

\section{Ageing Test and Analysis}

In previous section, we attributed battery ageing to external factors such as improper temperature, overcharge/overdischarge, high voltage storage, and even the load profile. Efforts have been made to characterize the relationship between them. However, all these factors affect battery in different manner. Moreover, cross-dependence among factors makes it more difficult to quantify the ageing behavior. Thus, environmental factors and their consequences were deeply studied. Following subsections give a brief review for the ageing tests and relationship between the factors and performance of aged batteries.

3.1. Performance during Cycle and Storage. Many researches on normal operation for Li-ion batteries were reported to understand the performance degradation during cycling and storage [25]. Bloom et al. [26] tried to find the mathematical relationship between extern conditions and performance degradation, in form of power fade and ASI (area specific impedance) increase. The author changed temperature and SOC during calendar tests while temperature and $\triangle$ SOC during cycle tests. All test data were fit into the equation, trying to build a life predication model:

$$
Q=A \exp \left(\frac{-E_{a}}{R T}\right) t^{z} \text {, where }
$$

$Q$ is the evaluated parameter, ASI or power.

In calendar test the fitted $z$ stayed around $1 / 2$ (varying from 0.46-0.61), following Arrhenius kinetics [27] so the ageing was considered due to SEI layer growth. However, during high SOC cycle $(\triangle \mathrm{SOC}=6 \%), z$ dropped to $1 / 10$, which indicated that more complex reaction occurred. Service lives of $\mathrm{Li}$-ion batteries in different conditions were predicated with the fitted equation.

\subsection{Performance at Extreme Environment}

3.2.1. Overcharge. More researches were carried out to evaluate one single factor, especially the extreme condition, on ageing. Because external energy is directly added into batteries, overcharge is considered as one of the most serious problems resulting in thermal runaway. Author in $[28,29]$ constructed "soft" overcharge strategy for a detailed study on overcharge. Irreversible changes could be observed at $150 \%$ overcharge and distraction of anode and cathode at $200 \%$ overdischarge, both of which induce irreversible loss of active material. Through examining the surface of recovered separator, author believed thermal runaway caused by overdischarge might result from microshorting initiated by growth penetrating through separator and accelerated side reactions at anode.

3.2.2. Overdischarge. Overdischarge barely induces thermal runaway directly. However, overdischarged cells experience irreversible capacity loss and changes of thermal stability, which may impact tolerance to abuse condition and increase the potential of safety issues. In order to verify the explanation in [30] about overdischarge, a series of overdischarge tests at $0.0-2.0 \mathrm{~V}$ were carried out in [31]. Irreversible capacity loss was observed differently according to its discharge cutoff voltage, and overdischarged cells represented an accelerated ageing trend under normal cycles. Furthermore, overdischarge to $0 \mathrm{~V}$ made an even worse condition where the behavior became unpredictable. After examining the separator, copper was found at the anode side, which indicated the possible cause of copper dissolution from collector.

3.2.3. Abnormal Temperature. Although Arrhenius theory is usually used for description of ageing, especially the effect of temperature, it may not be appropriate for all range of temperatures. Wide-ranged temperature tests show that the predominant ageing mechanism at low temperature is plating of metallic lithium at the anodes due to the slow ion diffusion, which is deduced from the measurement of negative polarization versus $\mathrm{Li} / \mathrm{Li}^{+}$with reference electrode. In this case, delivered energy and efficiency are lower, considering $60 \%$ at $-20^{\circ} \mathrm{C}$ compared with nearly $100 \%$ at room temperature [32], and it is difficult to charge a normal battery under $-25^{\circ} \mathrm{C}$. On the contrary, high temperature accelerated degradation of cathode and SEI growth at anode, resulting in the capacity fade. The degradation of performance usually exhibits two different slopes with inflexion at about $25^{\circ} \mathrm{C}$. Ramadass et al. [33] gave the full representation and explanation of performance for Li-ion batteries at $25^{\circ} \mathrm{C}, 45^{\circ} \mathrm{C}, 50^{\circ} \mathrm{C}$, and $55^{\circ} \mathrm{C}$, whose results are listed in Table 1 . From the table, the capacity loss is higher when battery suffers higher temperature. After 800 cycles, the cells at $25^{\circ} \mathrm{C}$ and $45^{\circ} \mathrm{C}$ lost about $31 \%$ and $36 \%$ of their initial capacity, while cell at $50^{\circ} \mathrm{C}$ lost more than $60 \%$ capacity after 600 cycles and cell at $55^{\circ} \mathrm{C}$ lost $70 \%$ after 500 cycles. The author attributed the loss to ohmic loss, secondary active material loss, and primary active material loss and quantified their contributions, respectively.

Even higher temperature (above $65^{\circ} \mathrm{C}$ ) cycle was tested. Capacity loss of $22 \%$ during 29 cycles was observed, which 
TABle 1: Capacity loss at different temperatures.

\begin{tabular}{lcccc}
\hline & $25^{\circ} \mathrm{C}$ & $45^{\circ} \mathrm{C}$ & $50^{\circ} \mathrm{C}$ & $55^{\circ} \mathrm{C}$ \\
\hline $150 \mathrm{cyc}$ & 107 & 125 & 141 & 168 \\
$300 \mathrm{cyc}$ & 182 & 209 & 427 & 481 \\
$800 \mathrm{cyc}$ & 539 & 643 & $1074(600)$ & $1255(490)$ \\
\hline
\end{tabular}

was attributed to positive electrode bind and composition changes in SEI [34].

3.2.4. High-Rate Cycling. Charging/discharging rate is an important factor especially for power applications. Highrate discharge usually means short period for Li-ion transfer. In this case ions are not fully deintercalated which results in capacity loss and lithium dendrite. Moreover, high rate current forms higher power consumption across the same internal resistor and accelerates the internal temperature increase. Side reactions will be enhanced so that loss of active material will result in battery degradation. So there is always a capacity fade and accelerated ageing when suffering high-rate discharge. The capacity fade at different rate was quantified in $[35,36]$ and deep researches were carried out to understand the relationship between current profiles and internal behaviors. In [37], different charging protocol was proposed to achieve a fast charging strategy with minimized degradation cost. Same approach was applied to discharging case, which showed that the driving mode had great influence on battery life $[38,39]$.

The high-rate related problem may be relieved through advanced nanotechnology. Carbon nanotube, as a unique 1D additive material for Li-ion batteries, not only increases contact area with electrolyte, but also reduces the transport path for ions and improves the insertion/removal rate. In this case, capacity loss originating from high-rate cycling is reduced.

3.2.5. Interactions. More and more researches have been focused on interactions among different ageing factors, because in real application, for example, EV or HEV, all these factors mentioned above always occur simultaneously. The temperature varies with climate and thermal management; load profile lies on the driving mode [40], and voltages of individual cells depend on the balancing protocol. Complex situation accelerates the performance degradation and makes the diagnosis ever harder. Li [41] took into account the following factors: ambient temperature, discharge rate, discharge cut-off voltage, charge rate, and charge cut-off voltage for battery ageing and tried to verify the coupling between these factors. However, the result seemed not satisfactory. The author in [42] also committed to find the coupling of cycling rate and low temperature. Moreover, he suggested that aged Li-ion batteries could only be deployable in secondlife applications only if their ageing history was known and appropriate tests were necessary. All these facts invoke further efforts on research about the ageing mechanism and relationship between performance degradation and related factors.

\section{Fault Diagnosis Methods for Li-Ion Batteries}

When a fault occurs, some variables in this system (direct or indirect) represent different behaviors from the ordinary case. Diagnosis system extracts the fault information from the difference and deals with the fault in time. Fault diagnosis is a critical topic which has been widely applied in mechanical, aerostatic, electrical, and military fields [43]. Main processes for fault diagnosis consist of fault feather extraction, fault isolation, and estimation as well as fault evaluation and decision. According to the principle of diagnosis methods, they can be classified as model based method and nonmodel based method. Classification of diagnosis technology can be found in Figure 2 [44].

4.1. Model Based Method. Through the difference between prior information from model and measured information from diagnosed object, residual signal is obtained and processed for fault information. This is the main principle of model based method which can be divided into state estimation and parameter estimation. There are essentially four types of common models: mathematical models, electrochemical models, equivalent circuit models, and experimental models. Each model has its own emphasis, for example, mathematical models are based on stochastic approaches or empirical equations; electrochemical models characterize internal kinetics and thermal behaviors while equivalent circuit models represent external response. Here we focus on equivalent circuit model for its clear physical meaning of parameters and less computation taken. One of the most common models is displayed in Figure 3 , where $R_{0}$ : Electrolyte Resistance, $C_{\mathrm{dl}}$ : Double Layer Capacity, $R_{\mathrm{ct}}$ : Charge Transfer Resistance, and $Z_{W}$ : Warburg Impedance. These parameters change according to the state of the cell and can be good indicators for battery ageing [45].

Author in [46] simplified Randles equivalent circuit model of Li-ion batteries and extracted interested parameters through impedance spectrum. After overcharge and discharge cycling tests, the effects of cycles on the parameters were summarized to form rule base and update proposed model. Finally fuzzy logic was applied to diagnose the overcharge and overdischarge fault during battery operation. The similar idea appeared in [47]. The author also performed a series of overcharge and overdischarge cycles and constructed models for normal operation and fault operation with Kalman filter. MMAE (multiple model adaptive estimation) was adopted for comparison of results from each model with actual result. Fault information was given in form of possibility. More fault modes can be solved through model based method if the fault pattern is known, for example, in [48], author tried to locate contact resistor fault.

\subsection{Nonmodel Based Method}

4.2.1. Signal Processing Based Method. The simplest idea of signal processing based method sets a threshold, if the target signal or its changing rate exceeds the threshold, a fault will be located. The work of [49] sets the upper and lower thresholds 


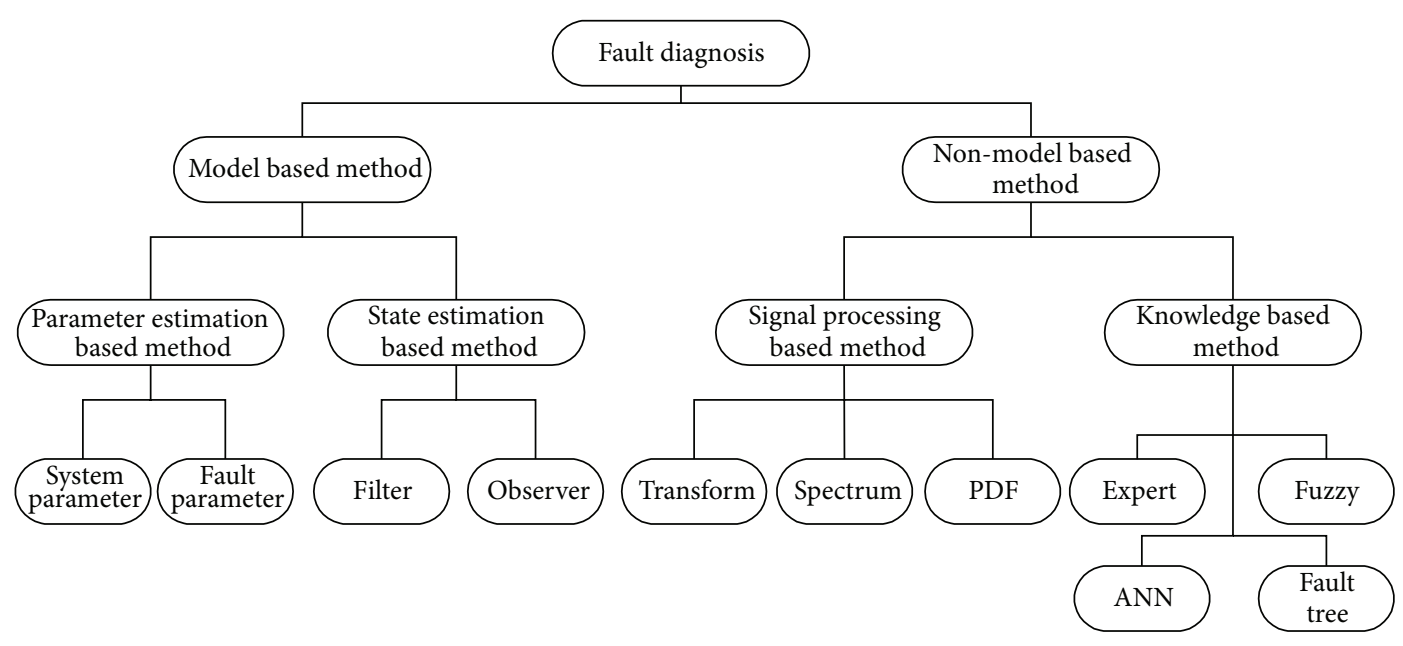

FIgUre 2: Typical classification of diagnosis technology.

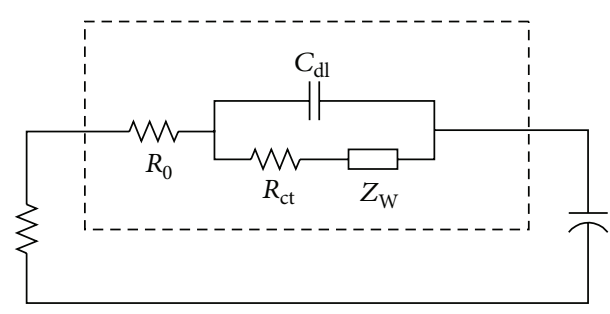

Figure 3: Randles Equivalent Circuit Model.

directly with the average value and average standard error. Individual parameters were monitored in real time to see if their values fell into permitted range.

However direct diagnosis method may be not suitable for complicated target whose fault symptom cannot be easily accessed. In this case the fault may be related to the amplitude, phase, frequency, or correlation of output signals. For instance, power spectrum will be affected by localized corrosion of rotating bearing. In this case analysis such as spectrum analysis, ARMA (autoregressive moving average), wavelet transform, and PDF (possibility distribution function) are the better ways to extract fault symptoms.

EIS (electrochemical impedance spectroscopy) is a powerful tool for battery analysis, and it provides abundant electrochemical information about different aging mechanism. However, it requires special equipment such as electrochemical station which limits its online applications. The author in [50] proposed an online impedance spectroscopy method of fault diagnosis for Li-ion batteries. Through applying a slight signal during charging and discharging cycles, frequency spectrum of current and voltage were obtained through DFT, with which impedance spectroscopy of target battery was calculated without any professional equipment or off-line requirement.

Wavelet transform has been widely applied in fault diagnosis for mechanical and electrical system, but barely adopted for that of Li-ion batteries. In [51], the author selected $\mathrm{dB} 3$ and scale 5 as wavelet function, and took the 5th level of approximation and detail as indicators of battery degradation. Wavelet process could be treated as signal decomposition through low-pass and high-pass filters so that the detailed information of operation profile at different frequency range were achieved. Finally a novel definition of $\mathrm{SOH}$ was given. The principle of wavelet transform is shown in Figure 5.

Other powerful signal processing tools such as impulse response [52], PDF [53], sliding mode observer [54] and support vector machine and relevance vector machine $[55$, 56] were applied in fault diagnosis for Li-ion batteries and made certain progress.

4.2.2. Knowledge Based Method. Knowledge based method has been developing rapidly these years and achieved great success in fault diagnosis with progress in artificial intelligence and expert system. By means of established historical database or expert experience, knowledge based method overcomes the dependence on accurate model and the requirement for huge computations. According to its diagnosis principle, it can be classified as follows:
(a) expert system;
(b) fuzzy logic;
(c) fault tree analysis;
(d) ANN (artificial neural network);
(e) information fusion technology.

As declared above, expert system induces the expert experience and heuristic knowledge to solve certain kind of problem. Usually it consists of knowledge base and inference engine as well as knowledge acquisition module and interpretation interface. In fault diagnosis expert system, fault feather of battery was analyzed according to huge amount of data, committed to construct an open knowledge database which connected the fault with symptoms [57]. After an intelligent and independent inference engine was constructed, the system showed effectiveness on battery fault 
diagnosis. Another expert system was also implemented in [58], unlike [57] the author applied the fuzzy logic and chose proper membership function to define the symptoms and faults, as well as a fuzzy relationship matrix to connect both domains. Rule database was achieved through experience, and fault membership could be calculated which determined the health status in form of DOF (degree of failure). Similar expert system could be seen also in [59] with diagnosis object of Li-ion batteries.

Not only the faults of batteries but also the faults from the whole battery management system attract researchers' attention. The accuracy of fault diagnosis system depends on the data acquisition element, so it's necessary for BMS to determine if the received data is reliable. $\mathrm{Hu}$ et al. [60] focused on temperature sensor failure during operation. The author adopted residual sensor and data fusion technology, and selected the optimal input to guarantee the system free from temperature sensor failure. Same technique may be available for voltage and current acquisition.

4.2.3. Comparison of Diagnosis System. All these introduced diagnosis methods for Li-ion batteries have made certain progress to improve the safety problem, but they still have limitations in real application, respectively. Model based method achieves a perfect performance towards linear system diagnosis, but diagnosis for nonlinear system remains a key problem in research field. Li-ion batteries, as a fully nonlinear electrochemical system, may not be solved with linear approach, so nonlinear theory, adaptive observer, and qualitative methods such as EKF (extended Kalman filter) have been adopted to improve the performance of model based method for quasinonlinear system. Besides, compromise between robustness and sensitivity of diagnosis system is another issue to be considered [61].

Signal processing based method avoids the difficulty in system modeling, which is simpler and has better dynamic performance. However, it has some difficulties on dealing with the early faults and fault location. Calculation requirement depends greatly on applied technology, but is always larger compared with model based method.

Knowledge based method suits well in case of complicated and nonlinear system. It takes experience and knowledge into consideration, which is a promising diagnosis method due to its artificial intelligence. On the contrary, training process or rule establishment is time consuming and has great influence on diagnosis accuracy. So there is still a long road ahead before its real application.

4.2.4. Module Diagnosis. Batteries need to be assembled into packs to provide enough capacity or power for consumer electronics and EV, so fault diagnosis towards module should be more meaningful [62-64]. However, due to the complexity of battery electrochemical characteristic and inhomogeneity among individual cells, researches on module diagnosis have been reported only in recent few years and are still developing. After a bridge between individual cells and battery pack was constructed, [65] constructed the model for individual cell and three cells were connected in series to form a string.
Parameter estimation of the "small module" was carried out in form of matrix.

System integration of battery pack is an important issue for system safety. Cells as well as contact condition and other assembly, will influence the system performance simultaneously. This problem was introduced in [66]. After acceleration test and continuous discharging test, the fault of individual cell occurred. The author not only provided a way to identify faulty cell in battery module, but also demonstrated the imbalances phenomena resulting from unequal current path in highly paralleled strips due to contact resistance. He suggested that careful module design and balancing strategy are necessary.

In this section, we demonstrate cons and pros of the common used diagnosis methods for Li-ion batteries and the difficulties for module diagnosis, with expectation for an accurate and practical diagnosis system in real applications. As we all know, Li-ion batteries are a complex electrochemical system which may not be sufficiently characterized by equivalent circuit model. And hardware limitation may not be adequate for huge computation or entire database storage. A hybrid approach may be the best solution if we merge the ideas together.

\section{Conclusion}

Faults of Li-ion batteries usually result from ageing process or abuse operation in form of internal impedance increment, power fade and capacity degradation [67]. This paper reviewed the battery ageing mechanisms with the purpose to connect external fault symptom with internal electrochemical property of Li-ion batteries. Main ageing factors such as overcharge/overdischarge, elevated temperature were analyzed to explain their relationship with ageing process and performance of Li-ion batteries. With good understanding of the fault origins and their symptoms summarized, fault diagnosis system could be realized.

Model based and non-model based approaches in fault diagnosis technology have been introduced, with their cons and pros. Model based can perform perfect diagnosis if the system model is known, especially the system is linear. When the system is complex and nonlinear, signal processing may be necessary to extract fault symptoms from real-time data with cost of huge computation. Knowledge based method can also be considered if historical database or expert system has been established. However, this establishment process may be time consuming. A hybrid approach may be wise to gain all the advantages of the method above. For example, equivalent circuit model is used for explanation of ageing process, whose ageing parameters are extracted through signal processing methods [68]. With reference of data from database and inference from expert system, ageing and fault diagnosis will be achieved (see Figure 4).

Therefore, safety issue for Li-ion batteries system is still a challenge due to the complexity of battery system. It requires further researches on (1) deep understanding of ageing mechanism and estimation method; (2) advanced manufacture technology for Li-ion batteries such as nanotubes and 


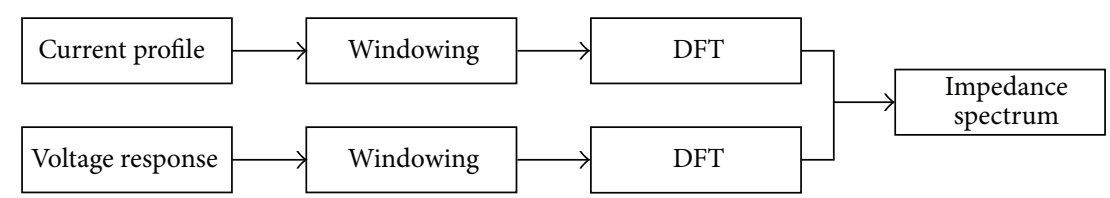

FIGURE 4: Signal processing method for impedance spectroscopy.

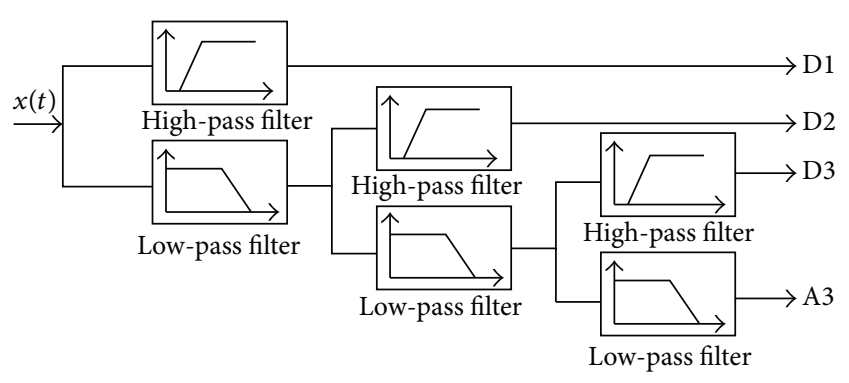

FIGURE 5: Block diagram of wavelet transform.

nanowalls to improve performance; and (3) accurate and reliable fault diagnosis approach merging the advantages of the method mentioned above.

\section{Additional Points}

A review of ageing mechanism of Li-ion batteries and diagnosis method for it is provided, covering the classic and newest researches in this field. The diagnosis methods are compared for establishment of a novel approach. The challenges for battery diagnosis are discussed.

\section{Conflict of Interests}

The authors declare no conflict of interests.

\section{Authors' Contribution}

Chao Wu reviewed the ageing mechanism of Li-ion batteries as well as diagnosis methods. Professor Chunbo Zhu made the contribution to establishment of the novel approach and discussion on challenges for battery diagnosis. Other authors provided the classic and newest researches in related field.

\section{Acknowledgment}

This research was supported by the Research and Development of Application Technology Plan Project in Heilongjiang Province of China (GA13A202) and the Science and Technology Project of State Grid Corporation of China.

\section{References}

[1] M. Bowkett, K. Thanapalan, T. Stockley, M. Hathway, and J. Williams, "Design and implementation of an optimal battery management system for hybrid electric vehicles," in Proceedings of the 19th International Conference on Automation and Computing (ICAC '13), pp. 212-216, London, UK, September 2013.

[2] H. F. Dai, X. L. Zhang, X. Z. Wei, Z. Sun, J. Wang, and F. Hu, "Cell-BMS validation with a hardware-in-the-loop simulation of lithium-ion battery cells for electric vehicles," International Journal of Electrical Power and Energy Systems, vol. 52, no. 1, pp. 174-184, 2013.

[3] W. Waag, S. Käbitz, and D. U. Sauer, "Experimental investigation of the lithium-ion battery impedance characteristic at various conditions and aging states and its influence on the application," Applied Energy, vol. 102, pp. 885-897, 2013.

[4] S. M. Rezvanizaniani, Z. Liu, Y. Chen, and J. Lee, "Review and recent advances in battery health monitoring and prognostics technologies for electric vehicle (EV) safety and mobility," Journal of Power Sources, vol. 256, pp. 110-124, 2014.

[5] Y. Xing, E. W. M. Ma, K.-L. Tsui, and M. Pecht, "An ensemble model for predicting the remaining useful performance of lithium-ion batteries," Microelectronics Reliability, vol. 53, no. 6, pp. 811-820, 2013.

[6] Q. Miao, L. Xie, H. J. Cui, W. Liang, and M. Pecht, "Remaining useful life prediction of lithium-ion battery with unscented particle filter technique," Microelectronics Reliability, vol. 53, no. 6, pp. 805-810, 2013.

[7] G. Jin, D. E. Matthews, and Z. Zhou, "A Bayesian framework for on-line degradation assessment and residual life prediction of secondary batteries in spacecraft," Reliability Engineering and System Safety, vol. 113, no. 1, pp. 7-20, 2013.

[8] V. Yufit, P. Shearing, R. W. Hamilton, P. D. Lee, M. Wu, and N. P. Brandon, "Investigation of lithium-ion polymer battery cell failure using X-ray computed tomography," Electrochemistry Communications, vol. 13, no. 6, pp. 608-610, 2011.

[9] C. Marino, J. Fullenwarth, L. Monconduit, and B. Lestriez, "Diagnostic of the failure mechanism in NiSb2 electrode for $\mathrm{Li}$ battery through analysis of its polarization on galvanostatic cycling," Electrochimica Acta, vol. 78, pp. 177-182, 2012.

[10] X. D. Liu, C. Z. Chen, Y. Y. Zhao, and B. Jia, "A review on the synthesis of manganese oxide nanomaterials and their applications on lithium-ion batteries," Journal of Nanomaterials, vol. 2013, Article ID 736375, 7 pages, 2013.

[11] A. Blyr, C. Sigala, G. Amatucci, D. Guyomard, Y. Chabre, and J.M. Tarascon, "Self-discharge of $\mathrm{LiMn}_{2} \mathrm{O}_{4} / \mathrm{C} \mathrm{Li}$-ion cells in their discharged state: understanding by means of three-electrode measurements," Journal of the Electrochemical Society, vol. 145, no. 1, pp. 194-209, 1998.

[12] Z. P. Wang, G. W. Xie, and L. J. Gao, "Electrochemical characterization of $\mathrm{Li}_{4} \mathrm{Ti}_{5} \mathrm{O}_{12} / \mathrm{C}$ anode material prepared by starch-solassisted rheological phase method for Li-ion battery," Journal of Nanomaterials, vol. 2012, Article ID 876197, 7 pages, 2012.

[13] J. M. Tarascon, W. R. McKinnon, F. Coowar, T. N. Bowmer, G. Amatucci, and D. Guyomard, "Synthesis conditions and oxygen stoichiometry effects on $\mathrm{Li}$ insertion into the spinel $\mathrm{LiMn}_{2} \mathrm{O}_{4}$," Journal of the Electrochemical Society, vol. 141, no. 6, pp. 14211431, 1994. 
[14] J. Park, J. H. Seo, G. Plett, W. Lu, and A. M. Sastry, "Numerical simulation of the effect of the dissolution of $\mathrm{LiMn}_{2} \mathrm{O}_{4}$ particles on Li-Ion battery performance," Electrochemical and Solid-State Letters, vol. 14, no. 2, pp. A14-A18, 2011.

[15] J. Christensen and J. Newman, "Cyclable lithium and capacity loss in li-ion cells," Journal of the Electrochemical Society, vol. 152, no. 4, pp. A818-A829, 2005.

[16] H.-P. Lin, D. Chua, M. Salomon et al., "Low-temperature behavior of Li-ion cells," Electrochemical and Solid-State Letters, vol. 4, no. 6, pp. 71-73, 2001.

[17] D. Aurbach, E. Zinigrad, Y. Cohen, and H. Teller, "A short review of failure mechanisms of lithium metal and lithiated graphite anodes in liquid electrolyte solutions," Solid State Ionics, vol. 148, no. 3-4, pp. 405-416, 2002.

[18] D. Aurbach, M. D. Levi, E. Levi et al., "Common electroanalytical behavior of $\mathrm{Li}$ intercalation processes into graphite and transition metal oxides," Journal of the Electrochemical Society, vol. 145, no. 9, pp. 3024-3034, 1998.

[19] M. N. Richard and J. R. Dahn, "Accelerating rate calorimetry study on the thermal stability of lithium intercalated graphite in electrolyte. I. Experimental," Journal of the Electrochemical Society, vol. 146, no. 6, pp. 2068-2077, 1999.

[20] T. Abe, H. Fukuda, Y. Iriyama, and Z. Ogumi, "Solvated Li-ion transfer at interface between graphite and electrolyte," Journal of the Electrochemical Society, vol. 151, no. 8, pp. A1120-A1123, 2004.

[21] Y. Wang, X. Guo, S. Greenbaum, J. Liu, and K. Amine, "Solid electrolyte interphase formation on lithium-ion electrodes. A $7 \mathrm{Li}$ nuclear magnetic resonance study," Electrochemical and Solid-State Letters, vol. 4, no. 6, pp. A68-A70, 2001.

[22] S. Bourlot, P. Blanchard, and S. Robert, "Investigation of aging mechanisms of high power Li-ion cells used for hybrid electric vehicles," Journal of Power Sources, vol. 196, no. 16, pp. 68416846, 2011.

[23] P. Liu, J. Wang, J. Hicks-Garner et al., "Aging Mechanisms of $\mathrm{LiFePO}_{4}$ batteries deduced by electrochemical and structural analyses," Journal of the Electrochemical Society, vol. 157, no. 4, pp. A499-A507, 2010.

[24] K. Edström, T. Gustafsson, and J. O. Thomas, "The cathodeelectrolyte interface in the Li-ion battery," Electrochimica Acta, vol. 50, no. 2-3, pp. 397-403, 2004.

[25] N. Khare, U. Banasthali, Jaipur, and R. Govil, "A battery storage system for fault tolerance," in Proceedings of the 29th International Telecommunications Energy Conference, Rome, Italy, September-October 2007.

[26] I. Bloom, B. W. Cole, J. J. Sohn et al., "An accelerated calendar and cycle life study of Li-ion cells," Journal of Power Sources, vol. 101, no. 2, pp. 238-247, 2001.

[27] B. Y. Liaw, E. P. Roth, R. G. Jungst, G. Nagasubramanian, H. L. Case, and D. H. Doughty, "Correlation of Arrhenius behaviors in power and capacity fades with cell impedance and heat generation in cylindrical lithium-ion cells," Journal of Power Sources, vol. 119-121, pp. 874-886, 2003.

[28] D. Belov and M.-H. Yang, "Failure mechanism of Li-ion battery at overcharge conditions," Journal of Solid State Electrochemistry, vol. 12, no. 7-8, pp. 885-894, 2008.

[29] D. Belov and M. H. Yang, "Investigation of the kinetic mechanism in overcharge process for Li-ion battery," Solid State Ionics, vol. 179, no. 27-32, pp. 1816-1821, 2008.
[30] M. Zhao, H. D. Dewald, F. R. Lemke, and R. J. Staniewicz, "Electrochemical stability of graphite-coated copper in lithiumion battery electrolytes," Journal of the Electrochemical Society, vol. 147, no. 11, pp. 3983-3988, 2000.

[31] H. Maleki and J. N. Howard, "Effects of overdischarge on performance and thermal stability of a Li-ion cell," Journal of Power Sources, vol. 160, no. 2, pp. 1395-1402, 2006.

[32] H.-P. Lin, D. Chua, M. Salomon et al., "Low-temperature behavior of Li-ion cells," Electrochemical and Solid-State Letters, vol. 4, no. 6, pp. 71-73, 2001.

[33] P. Ramadass, B. Haran, R. White, and B. N. Popov, "Capacity fade of Sony 18650 cells cycled at elevated temperatures: part II. Capacity fade analysis," Journal of Power Sources, vol. 112, no. 2, pp. 614-620, 2002.

[34] D. P. Abraham, E. M. Reynolds, P. L. Schultz, A. N. Jansen, and D. W. Dees, "Temperature dependence of capacity and impedance data from fresh and aged high-power lithium-ion cells," Journal of the Electrochemical Society, vol. 153, no. 8, pp. A1610-A1616, 2006.

[35] M. Zackrisson, L. Avellán, and J. Orlenius, "Life cycle assessment of lithium-ion batteries for plug-in hybrid electric vehicles-critical issues," Journal of Cleaner Production, vol. 18, no. 15, pp. 1517-1529, 2010.

[36] X. B. Han, M. G. Ouyang, L. G. Lu, and J. Q. Li, “Cycle life of commercial lithium-ion batteries with lithium titanium oxide anodes in electric vehicles," Energies, vol. 7, no. 8, pp. 4895-4909, 2014.

[37] B. Lunz, Z. Yan, J. B. Gerschler, and D. U. Sauer, "Influence of plug-in hybrid electric vehicle charging strategies on charging and battery degradation costs," Energy Policy, vol. 46, pp. 511519, 2012.

[38] Z. G. Yang and S. P. Wang, "High cycling performance cathode material: interconnected $\mathrm{LiFePO}_{4} /$ Carbon nanoparticles fabricated by sol-gel method," Journal of Nanomaterials, vol. 2014, Article ID 801562, 7 pages, 2014.

[39] J. C. Arrebola, A. Caballero, L. Hernán, and J. Morales, "Improving the performance of lithium-ion batteries by using spinel nanoparticles," Journal of Nanomaterials, vol. 2008, Article ID 659397, 10 pages, 2008.

[40] M. Ecker, J. B. Gerschler, J. Vogel et al., "Development of a lifetime prediction model for lithium-ion batteries based on extended accelerated aging test data," Journal of Power Sources, vol. 215, pp. 248-257, 2012.

[41] Z. Li, Characterization research of $\mathrm{LiFePO}_{4}$ batteries for application on pure electric vehicles [Ph.D. thesis], Tsinghua University, Beijing, China, 2011.

[42] Y. M. Zhang and J. Jiang, "Issues on integration of fault diagnosis and reconfigurable control in active fault-tolerant control systems," in Proceedings of the 6th IFAC Symposium on Fault Detection, Supervision and Safety of Technical Processes (SAFEPROCESS '06), pp. 1437-1448, Beijing, China, September 2006.

[43] N. Williard, W. He, M. Osterman, and M. Pecht, "Reliability and failure analysis of Lithium Ion batteries for electronic systems," in Proceedings of the 13th International Conference on Electronic Packaging Technology and High Density Packaging (ICEPT-HDP '12), pp. 1051-1055, Guilin, China, August 2012.

[44] C. H. Hu and H. L. Xu, Design and Analysis of Fault-Tolerant Control and Fault Diagnosis for Control System, National Defense Industry Press, Beijing, China, 2008.

[45] Z. W. He, M. Y. Gao, C. S. Wang, L. Y. Wang, and Y. Liu, "Adaptive state of charge estimation for Li-ion batteries based 
on an unscented kalman filter with an enhanced battery model," Energies, vol. 6, no. 8, pp. 4134-4151, 2013.

[46] T. C. Kaypmaz and R. N. Tuncay, "An advanced cell model for diagnosing faults in operation of Li-ion polymer batteries," in Proceedings of the 7th IEEE Vehicle Power and Propulsion Conference (VPPC '11), pp. 1-5, Chicago, Ill, USA, September 2011.

[47] A. Singh, A. Izadian, and S. Anwar, "Fault diagnosis of LiIon batteries using multiple-model adaptive estimation," in Proceedings of the 39th Annual Conference of the IEEE Industrial Electronics Society (IECON '13), pp. 3524-3529, November 2013.

[48] S. A. Gadsden and S. R. Habibi, "Model-based fault detection of a battery system in a hybrid electric vehicle," in Proceedings of the 7th IEEE Vehicle Power and Propulsion Conference (VPPC '11), pp. 1-6, IEEE, Chicago, Ill, USA, September 2011.

[49] J.-C. Hwang, J.-C. Chen, J.-S. Pan, and Y.-C. Huang, "Measurement method for online battery early faults precaution in uninterrupted power supply system," IET Electric Power Applications, vol. 5, no. 3, pp. 267-274, 2011.

[50] U. Tröltzsch, O. Kanoun, and H. R. Tränkler, "Characterizing aging effects of lithium ion batteries by impedance spectroscopy," Electrochimica Acta, vol. 51, no. 8-9, pp. 1664-1672, 2006.

[51] J. Kim and B. H. Cho, "An innovative approach for characteristic analysis and state-of-health diagnosis for a Li-ion cell based on the discrete wavelet transform," Journal of Power Sources, vol. 260, pp. 115-130, 2014.

[52] A. Banaei and B. Fahimi, "Real time condition monitoring in Li-ion batteries via battery impulse response," in Proceedings of the IEEE Vehicle Power and Propulsion Conference (VPPC '10), pp. 1-6, Lille, France, September 2010.

[53] T. A. Moebes, "Lithium battery analysis: probability of failure assessment using logistic regression," in Proceedings of the Annual Reliability and Maintainability Symposium (RAMS '11), 5, p. 1, Vista, Fla, USA, January 2011.

[54] D. Kim, K. H. Koo, J. J. Jeong, T. D. Goh, and S. W. Kim, "Second-order discrete-time sliding mode observer for state of charge determination based on a dynamic resistance Li-ion battery model," Energies, vol. 6, no. 10, pp. 5538-5551, 2013.

[55] A. Widodo, M.-C. Shim, W. Caesarendra, and B.-S. Yang, "Intelligent prognostics for battery health monitoring based on sample entropy," Expert Systems with Applications, vol. 38, no. 9, pp. 11763-11769, 2011.

[56] J. I. Park, S. H. Baek, M. K. Jeong, and S. J. Bae, "Dual features functional support vector machines for fault detection of rechargeable batteries," IEEE Transactions on Systems, Man and Cybernetics Part C: Applications and Reviews, vol. 39, no. 4, pp. 480-485, 2009.

[57] X. J. Liu, Research and application of intelligent battery fault diagnosis system [M.S. dissertation], Beijing University of Posts and Telecommunications, Beijing, China, 2010.

[58] W. J. Liu, Research and implementation of failure diagnosis expert system for battery pack [M.S. thesis], Hunan University, Hunan, China, 2005.

[59] J. R. Wu, Design of remote monitoring system and study on fault diagnosis method for electric vehicle [M.S. thesis], Jilin University, Jilin, China, 2011.

[60] C. H. Hu, R. He, R. C. Wang, and J. B. Yu, "Fault prediction and fault-tolerant of lithium-ion batteries temperature failure for electric vehicle," in Proceedings of the 3rd International Conference on Digital Manufacturing and Automation (ICDMA '12), pp. 410-413, Guilin, China, August 2012.
[61] B. Wu, G. J. Offer, V. Yufit, D. A. Howey, and N. P. Brandon, "Fault analysis in battery module design for electric and hybrid vehicles," in Proceedings of the 6th IET International Conference on Power Electronics, Machines and Drives (PEMD '12), pp. 1-6, IET, Bristol, UK, March 2012.

[62] J. López, R. Navarro, J. M. Gallego, F. Parres, and S. Ferrándiz, "Failure analysis of automotive battery parts," Engineering Failure Analysis, vol. 16, no. 7, pp. 2217-2223, 2009.

[63] Z. Q. Chen, F. Lin, C. S. Wang, Y. L. Wang, and M. Xu, "Active diagnosability of discrete event systems and its application to battery fault diagnosis," IEEE Transactions on Control Systems Technology, vol. 22, no. 5, pp. 1892-1898, 2014.

[64] L. Ahmadi, M. Fowler, S. B. Young, R. A. Fraser, B. Gaffney, and S. B. Walker, "Energy efficiency of Li-ion battery packs re-used in stationary power applications," Sustainable Energy Technologies and Assessments, vol. 8, pp. 9-17, 2014.

[65] W. Chen, W.-T. Chen, M. Saif, M.-F. Li, and H. Wu, "Simultaneous fault isolation and estimation of lithium-ion batteries via synthesized design of Luenberger and learning observers," IEEE Transactions on Control Systems Technology, vol. 22, no. 1, pp. 290-298, 2014.

[66] S. Buller, M. Thele, R. W. A. A. de Doncker, and E. Karden, "Impedance-based simulation models of supercapacitors and liion batteries for power electronic applications," IEEE Transactions on Industry Applications, vol. 41, no. 3, pp. 742-747, 2005.

[67] D. Mukoyama, T. Momma, H. Nara, and T. Osaka, "Electrochemical impedance analysis on degradation of commercially available lithium ion battery during chargedischarge cycling," Chemistry Letters, vol. 41, no. 4, pp. 444-446, 2012.

[68] D. Andre, A. Nuhic, T. Soczka-Guth, and D. U. Sauer, "Comparative study of a structured neural network and an extended Kalman filter for state of health determination of lithium-ion batteries in hybrid electricvehicles," Engineering Applications of Artificial Intelligence, vol. 26, no. 3, pp. 951-961, 2013. 

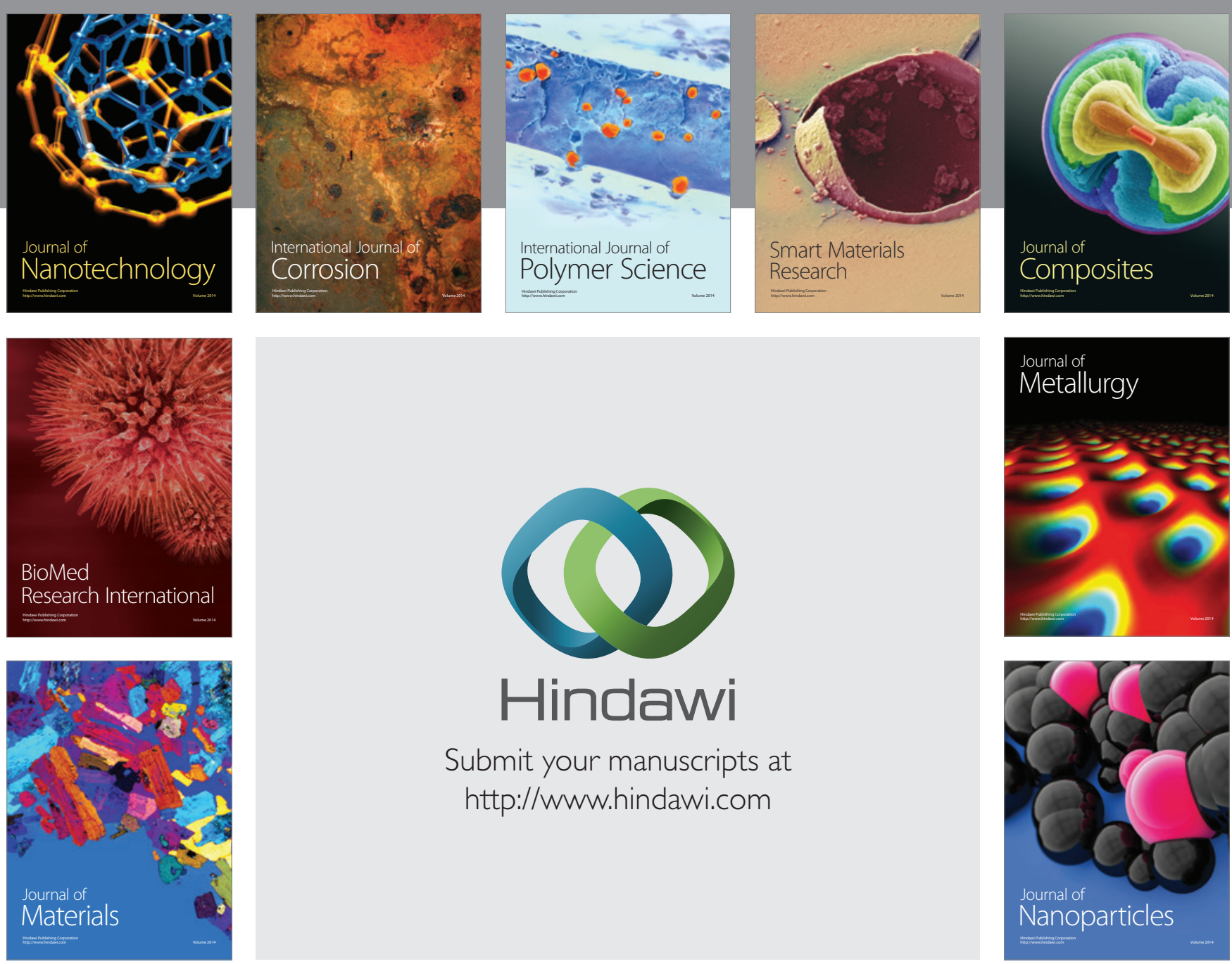

Submit your manuscripts at http://www.hindawi.com
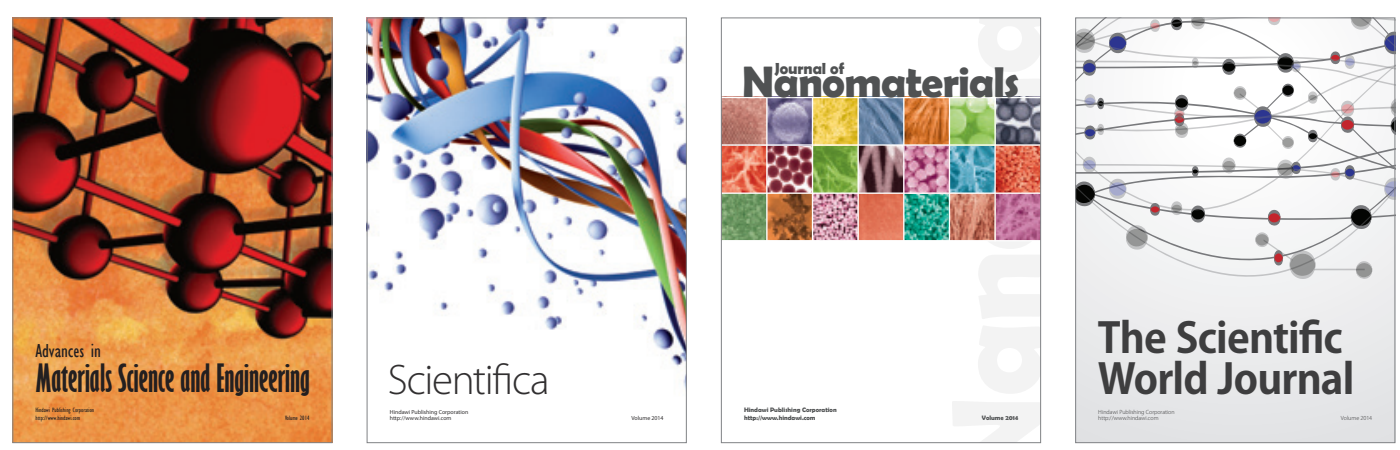

\section{The Scientific World Journal}
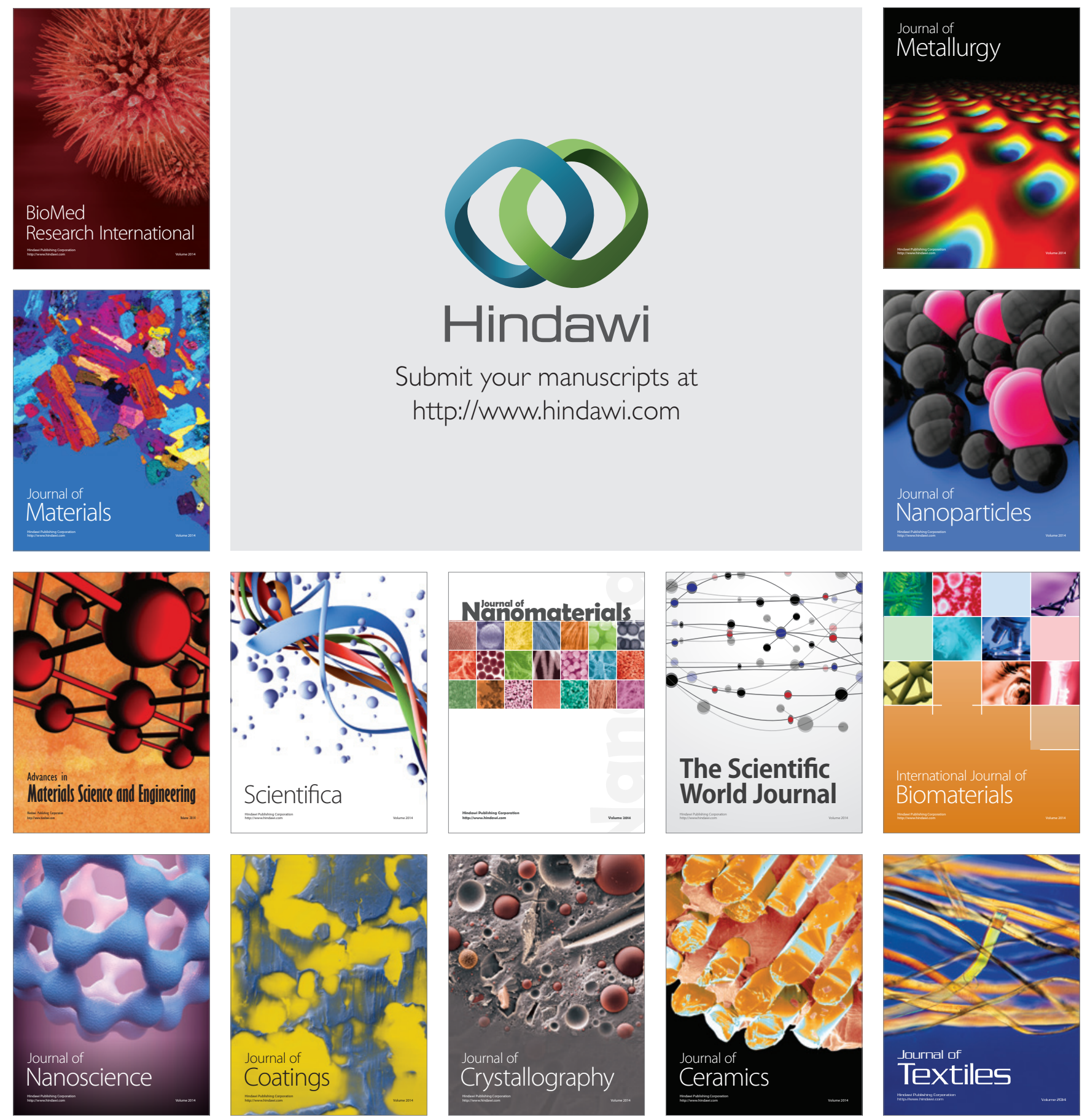